\title{
Perceptual and Acoustic Outcomes of Early-Stage Glottic Cancer After Laser Surgery or Radiotherapy: A Meta-Analysis
}

\author{
So Hyun Lee ${ }^{1}$ (1) $\cdot$ Ki Hwan Hong ${ }^{2,3} \cdot$ Jong Seung Kim²,3 $\cdot$ Yong Tae Hong ${ }^{2,3}$ (i) \\ Departments of ${ }^{1}$ Speech Pathology and ${ }^{2}$ Otolaryngology-Head and Neck Surgery, and \\ ${ }^{3}$ Research Institute of Clinical Medicine, Chonbuk National University-Chonbuk National University Hospital, Jeonju, Korea
}

\begin{abstract}
Laser surgery (LS) or radiotherapy (RT) is normally recommended in early glottic cancer. The objective of this study was to perform a comprehensive meta-analysis of acoustic and perceptual outcomes to compare voice quality of LS or RT in early-stage glottic cancer. Data sources were obtained after searching PubMed, Google Scholar, EBSCO, and RISS using the following search terms: glottic cancer, glottic carcinoma, endoscopic surgery, laser surgery, radiotherapy, radiation, voice, voice quality, and grade, roughness, breathiness, asthenia, and strain (GRBAS) scale. Articles that compared voice outcomes between LS and RT were identified. This meta-analysis included 15 articles with 744 patients, including 400 in the LS group and 344 in the RT group. Random effects models were selected. Forest plots included standardized mean differences, standard errors, variance, 95\% confidence intervals (lower limit to upper limit), z-values, and $P$-values. In perceptual analysis, grade $(\mathrm{G})$ and asthenia (A) of RT were significantly better than LS. There was no statistically significant difference in roughness (R), breath (B), or strain (S) between LS and RT groups. Jitter, shimmer, and noise to harmonic ratio measurements showed significant differences, resulting in enhanced posttreatment effect of RT compared to LS. Results of our meta-analysis suggested that RT might lead to superior voice quality than LS in early glottic cancer.
\end{abstract}

Keywords. Laser Surgery; Radiotherapy; Voice Quality; Meta-Analysis

\section{INTRODUCTION}

Laryngeal carcinoma is one of the most common head and neck cancers. It was estimated that 151,000 new cases (approximately 2.0 men and 0.3 women in every 100,000 population) of laryngeal carcinoma were diagnosed worldwide in 2008 [1]. Glottic carcinoma represents the majority of laryngeal cancer cases. It is mainly confined to the anterior portion of the vocal cord [2]. Early symptom of glottic carcinoma is hoarseness that can be diagnosed at early-stage of the disease. Laryngeal cancer has a fairly good prognosis among malignancies of the head and neck

\footnotetext{
- Received June 27, 2018

Revised November 16, 2018

Accepted December 16, 2018

- Corresponding author: YongTae Hong

Research Institute for Clinical Medicine, Chonbuk National

University-Biomedical Research Institute, Chonbuk National University

Hospital, 20 Geonji-ro, Deokjin-gu, Jeonju 54907, Korea

Tel: +82-63-250-1990, Fax: +82-63-250-1986

E-mail: centennialman@hanmail.net
}

if prompt and appropriate treatment is provided during the early stage [3-5]. Early detection and treatment can lead to a cure rate of $90 \%-95 \%$ with maximal voice preservation [4].

Several studies using objective and subjective analyses have focused on voice quality of patients with glottic carcinomas after laser surgery (LS) and radiotherapy (RT). In previous metaanalyses investigating voice quality, posttreatment favored external radiation rather than transoral laser surgical excision [6]. One study has shown no clinical difference in voice quality between transoral LS and external radiation [7]. Huang et al. [8] have compared patients treated with LS and RT and found no clear difference in jitter or shimmer. However, in meta-analysis of maximum phonation time (MPT), fundamental frequency differences were observed between the two groups [8]. Patients who had undergone RT showed increased MPT and decreased frequency (F0) compared to those with LS. LS generally results in loss of tissue while RT leads to vocal fold fibrosis and muscle fatigue [9]. The objective of the present meta-analysis was to evaluate voice quality of LS and RT based on the grade, rough-

Copyright @ 2019 by Korean Society of Otorhinolaryngology-Head and Neck Surgery.

This is an open-access article distributed under the terms of the Creative Commons Attribution Non-Commercial License (http://creativecommons.org/licenses/by-nc/4.0)

which permits unrestricted non-commercial use, distribution, and reproduction in any medium, provided the original work is properly cited. 
ness, breathiness, asthenia, and strain (GRBAS) scale and acoustic analysis parameters including frequency-perturbation (jitter), measures of amplitude-perturbation (shimmer), and noise to harmonic ratio (NHR). Results of this study can allow patients diagnosed with glottic carcinomas to select an effective treatment in terms of voice quality, provided both LS and RT are equally effective in treating the cancer.

\section{MATERIALS AND METHODS}

\section{Search strategy}

The search was limited to reports published in English and Korean languages. The following databases were searched: PubMed, Google Scholar, EBSCO, and RISS. References were searched for relevant articles through January 2018. The search was conducted using the following terms: glottic cancer, glottic carcinoma, endoscopic surgery, laser surgery, radiotherapy, radiation, voice, voice quality, and GRBAS. Full-texts and abstracts of all potentially relevant trials were obtained. References to previous meta-analyses were also reviewed to identify additional studies relevant to this meta-analysis.

\section{Study selection}

In this article, 15 comparative cohort articles published from 1994 to 2017 were included. All studies included in this study met the following inclusion criteria: (1) patients with previously untreated glottic cancer (based on the TNM system); (2) comparative studies using LS or RT as the first treatment for glottic cancer; (3) voice outcome measures including acoustic analysis (jitter, shimmer, NHR, and/or perceptual analysis (GRBAS); and (4) articles written in English or Korean languages.

\section{Data extraction}

Study characteristics and parameters related to acoustic voice analysis and perceptual analysis were extracted from included studies by a single author. The following information was ob-

\section{H I}

- A comprehensive meta-analysis of perceptual and acoustic outcomes to compare the voice quality of laser surgery or radiotherapy in early-stage glottic cancer.

- This meta-analysis included 15 articles, enrolled 744 patients including 400 in the laser surgery group and 344 in the radiotherapy group.

- Grade, asthenia, jitter, shimmer and noise to harmonic ratio of radiotherapy were significantly better than those of laser surgery.

- Our meta-analysis suggested that radiotherapy may be superior in voice quality than laser surgery in early glottic cancer. tained study name, publication year, number of patients, pathological stage, sex, age, follow-up time, acoustic analysis parameters (jitter, shimmer, and NHR), and perceptual analysis parameters (GRBAS).

\section{Statistical analysis}

All statistical analyses were performed using Comprehensive Meta-Analysis software ver. 2.2.064 (Biostat, Englewood, NJ, USA). Data were reported as mean and standard deviation or $P$-value were adopted for jitter, shimmer, NHR, and GRBAS of LS and RT groups. All data were calculated using the random effects model. Continuous data variables were compared using standardized mean differences (SMDs), standard error (SE), and 95\% confidence intervals (CIs). Publication bias of the article was assessed by funnel plots.

\section{RESULTS}

\section{Eligible studies and study characteristics}

In this meta-analysis, 15 articles were included. Reasons for exclusion are shown in Fig. 1. A total of 744 patients were enrolled, including 400 in the LS group and 344 in the RT group. Characteristics of studies are shown in Table 1 [10-24]. In Figs. 2-9, studies favoring LS and RT are indicated by A and B, respectively.

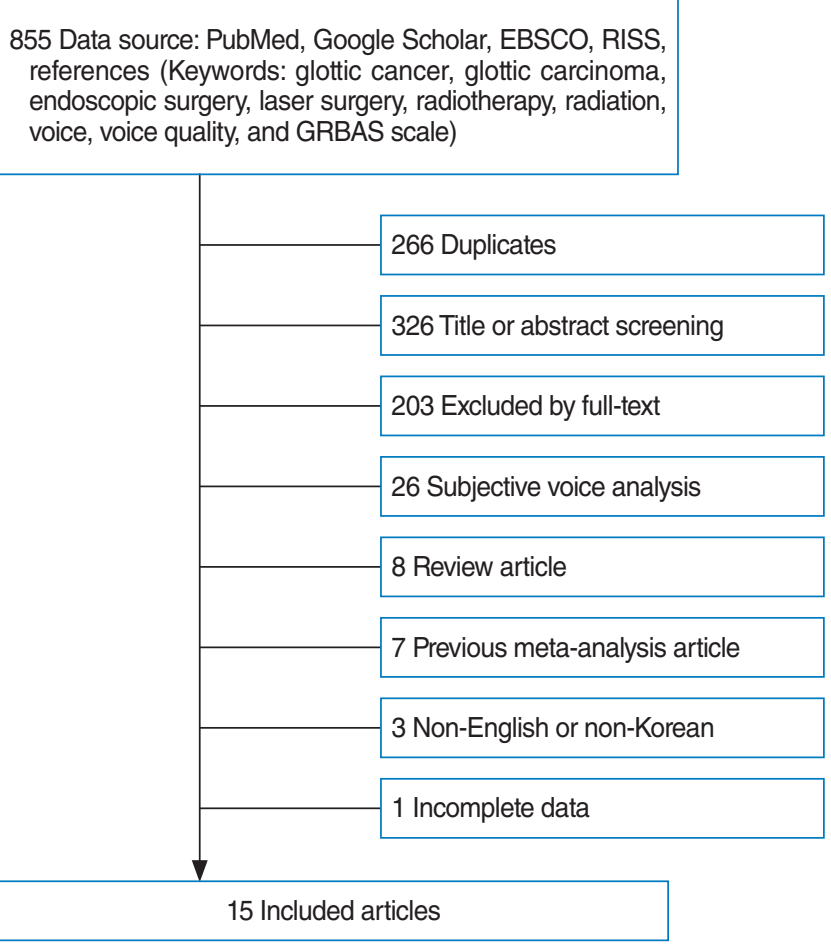

Fig. 1. Flowchart of selection. GRBAS, grade, roughness, breathiness, asthenia, and strain. 


\section{Perceptual analysis}

Perceptual analysis using GRBAS scale is an important method for voice quality measurement. Voice quality was assessed on the GRBAS scale based on grade $(G)$, roughness $(R)$, breathiness (B), asthenia (A), and strain (S). Ratings based on these five aspects of voice quality varied from 0 (normal), to 1 (mild), 2 (moderate), and 3 (severe) [10-12].

Six studies provided adequate data related to $G$ and $R$ with 193 patients in the LS group and 163 patients in the RT group. Parameter B was included in seven studies available. Five studies involved perceptual analysis of A and S with 175 patients in the LS group and 147 patients in the RT group. Parameter G $(\mathrm{SMD}=0.266, \mathrm{SE}=0.112$, variance $=0.012,95 \% \mathrm{CI}: 0.047$ to
0.484, z-value $=2.385, P=0.017$ ) (Fig. 2) showed a significant difference between the two treatment groups. The effect size of RT was higher than that of LS. Parameter R was not significantly different between the two groups (SMD $=0.016, \mathrm{SE}=0.111$, variance $=0.012,95 \% \mathrm{CI}:-0.202$ to 0.233 , $\mathrm{z}$-value $=0.141$, $P=0.888$ ) (Fig. 3). Fig. 4 indicates parameter B. In terms of parameter $\mathrm{B}(\mathrm{SMD}=0.189, \mathrm{SE}=0.111$, variance $=0.012,95 \% \mathrm{CI}$ : -0.028 to 0.406 , $\mathrm{z}$-value $=1.709, P=0.087$ ), no significantly difference in treatment effect was observed between LS and RT groups. Significant differences in A $(\mathrm{SMD}=0.257, \mathrm{SE}=0.115$, variance $=0.013,95 \%$ CI: 0.033 to 0.482 , $\mathrm{z}$-value $=2.247$, $P=0.025$ ) (Fig. 5) were observed between the two treatment groups. As shown in Fig. 8, RT treatment was more effective

Table 1. Eligible studies and characteristic of studies

\begin{tabular}{|c|c|c|c|c|c|c|c|c|c|}
\hline \multirow{2}{*}{ Study } & \multirow{2}{*}{$\begin{array}{l}\text { Pathological } \\
\text { stage }\end{array}$} & \multicolumn{2}{|c|}{ Total no. of patients } & \multicolumn{2}{|c|}{ Male:female } & \multicolumn{2}{|c|}{ Age (yr) } & \multicolumn{2}{|c|}{ Follow-up (mo) } \\
\hline & & LS & RT & LS & RT & LS & RT & LS & RT \\
\hline Ma et al. (2017) [16] & Tis, T1a, T1b, T2 & 55 & 47 & $50: 5$ & $40: 7$ & $65.1 \pm 11.4$ & $69.8 \pm 12.4$ & $\geq 24.0$ & $\geq 24.0$ \\
\hline Kono et al. (2016) [13] & T1a & 37 & 27 & $33: 4$ & $22: 5$ & NA & $69 \pm 9.8$ & $\geq 24.0$ & $\geq 24.0$ \\
\hline Aaltonen et al. (2014) [15] & T1a & 31 & 25 & NA & NA & 69.0 & 61.0 & NA & NA \\
\hline van Gogh et al. (2012) [17] & T1a & 67 & 39 & $67: 0$ & $39: 0$ & 66.0 & 65.0 & 24.0 & 24.0 \\
\hline Luo et al. (2012) [10] & T1a, T1b, T2 & 18 & 24 & $17: 1$ & $23: 1$ & $68.6 \pm 12.6$ & $67.6 \pm 11.4$ & $\geq 12.0$ & $\geq 12.0$ \\
\hline Czecior et al. (2012) [11] & Tis, $\mathrm{T} 1$ & 33 & 30 & NA & NA & 63 & 69 & NA & NA \\
\hline Ahn et al. (2012) [12] & T1a, T1b, T2 & 27 & 39 & NA & NA & NA & NA & 17.87 & 17.87 \\
\hline Sjogren et al. (2008) [14] & T1a & 18 & 16 & $14: 4$ & $13: 3$ & 67.0 & 69.0 & $\geq 36.0$ & $\geq 36.0$ \\
\hline Nunez Batalla et al. (2008) [18] & $\mathrm{T} 1 \mathrm{a}, \mathrm{T} 1 \mathrm{~b}$ & 19 & 18 & $19: 0$ & $18: 0$ & 64.0 & 67.0 & 30.0 & 40.0 \\
\hline Krengli et al. (2004) [19] & T1a & 30 & 27 & $29: 1$ & $26: 1$ & 67.5 & 69.0 & 62.0 & 60.0 \\
\hline Tamura et al. (2003) [20] & T1a & 14 & 6 & $14: 0$ & $6: 0$ & 69.0 & 71.0 & $\geq 12.0$ & $\geq 12.0$ \\
\hline Wedman et al. (2002) [21] & T1a & 15 & 9 & $15: 0$ & $9: 0$ & 72.0 & 70.0 & $\geq 24.0$ & $\geq 24.0$ \\
\hline Rosier et al. (1998) [22] & $\mathrm{T} 1 \mathrm{a}, \mathrm{T} 1 \mathrm{~b}$ & 7 & 6 & NA & NA & NA & NA & $\geq 48.0$ & $\geq 48.0$ \\
\hline Rydell et al. (1995) [23] & T1a & 18 & 18 & $18: 0$ & $18: 0$ & 65.2 & 63.9 & 12.0 & 12.0 \\
\hline McGuirt et al. (1994) [24] & T1a & 11 & 13 & $11: 0$ & $13: 0$ & NA & NA & $\geq 6.0$ & $\geq 6.0$ \\
\hline
\end{tabular}

Values are presented as number or mean \pm standard deviation.

LS, laser surgery; RT, radiotherapy; NA, not available.

Meta Analysis

\begin{tabular}{|c|c|c|c|c|c|c|c|c|c|c|c|c|}
\hline \multirow[t]{2}{*}{ Study name } & \multicolumn{7}{|c|}{$\underline{\text { Statistics for each study }}$} & \multicolumn{5}{|c|}{ Std diff in means and $95 \% \mathrm{Cl}$} \\
\hline & $\begin{array}{l}\text { Std diff } \\
\text { in means }\end{array}$ & $\begin{array}{l}\text { Standard } \\
\text { error }\end{array}$ & Variance & $\begin{array}{l}\text { Lower } \\
\text { limit }\end{array}$ & $\begin{array}{l}\text { Upper } \\
\text { limit }\end{array}$ & Z-Value & p-Value & & & & & \\
\hline Aaltonen 2014 & 1.228 & 0.293 & 0.086 & 0.654 & 1.802 & 4.194 & 0.000 & & & & & $\Rightarrow$ \\
\hline Czecior 2012 & 0.464 & 0.256 & 0.065 & -0.037 & 0.965 & 1.817 & 0.069 & & & & & \\
\hline Elisabeth V 2008 & 0.408 & 0.469 & 0.220 & -0.512 & 1.328 & 0.869 & 0.385 & & & & & \\
\hline Faustino 2007 & 0.749 & 0.340 & 0.116 & 0.082 & 1.415 & 2.200 & 0.028 & & & & & \\
\hline Yue Ma 2017 & -0.449 & 0.201 & 0.040 & -0.843 & -0.055 & -2.232 & 0.026 & & 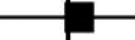 & & & \\
\hline \multirow[t]{4}{*}{ T Kono 2016} & 0.176 & 0.254 & 0.064 & -0.321 & 0.673 & 0.693 & 0.488 & & & & & \\
\hline & 0.266 & 0.112 & 0.012 & 0.047 & 0.484 & 2.385 & 0.017 & & & & & \\
\hline & & & & & & & & -1.00 & -0.50 & 0.00 & 0.50 & 1.00 \\
\hline & & & & & & & & & Favours A & & Favours B & \\
\hline
\end{tabular}

Fig. 2. Forest plot of grade. Std diff, standardized difference; $\mathrm{Cl}$, confidence interval. 
Meta Analysis

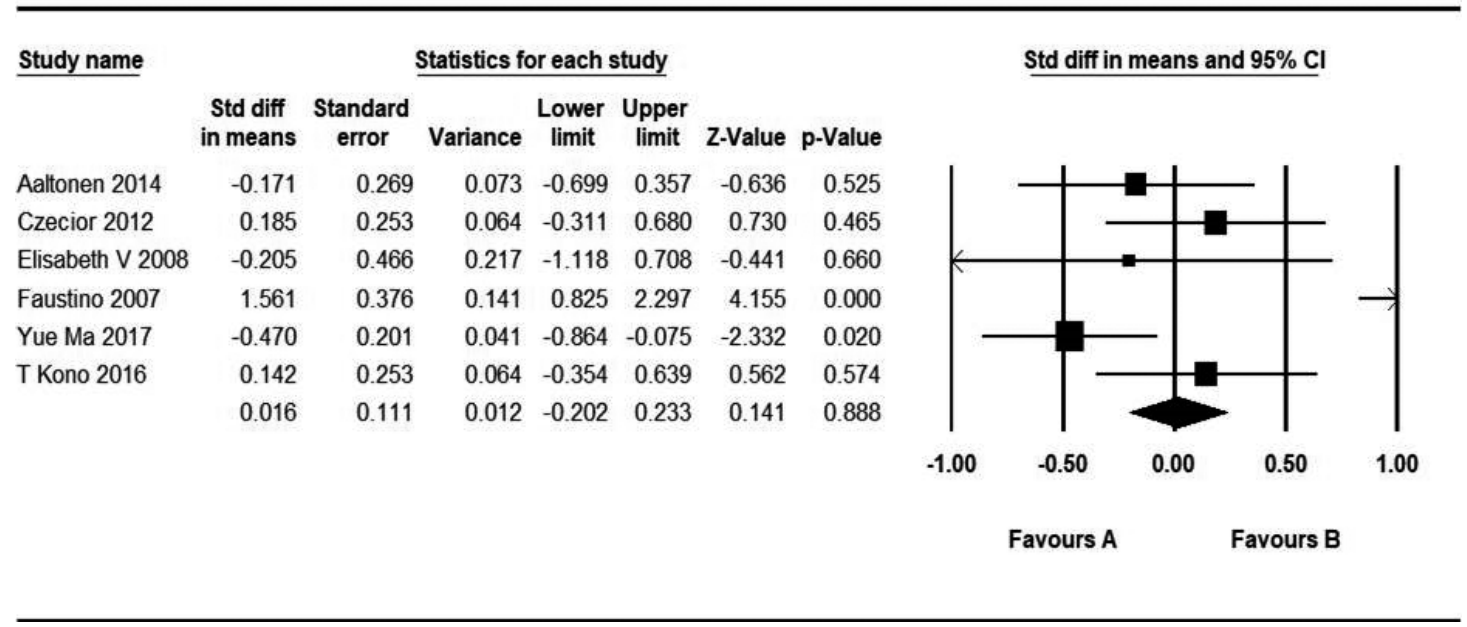

Fig. 3. Forest plot of roughness. Std diff, standardized difference; $\mathrm{Cl}$, confidence interval.

Meta Analysis

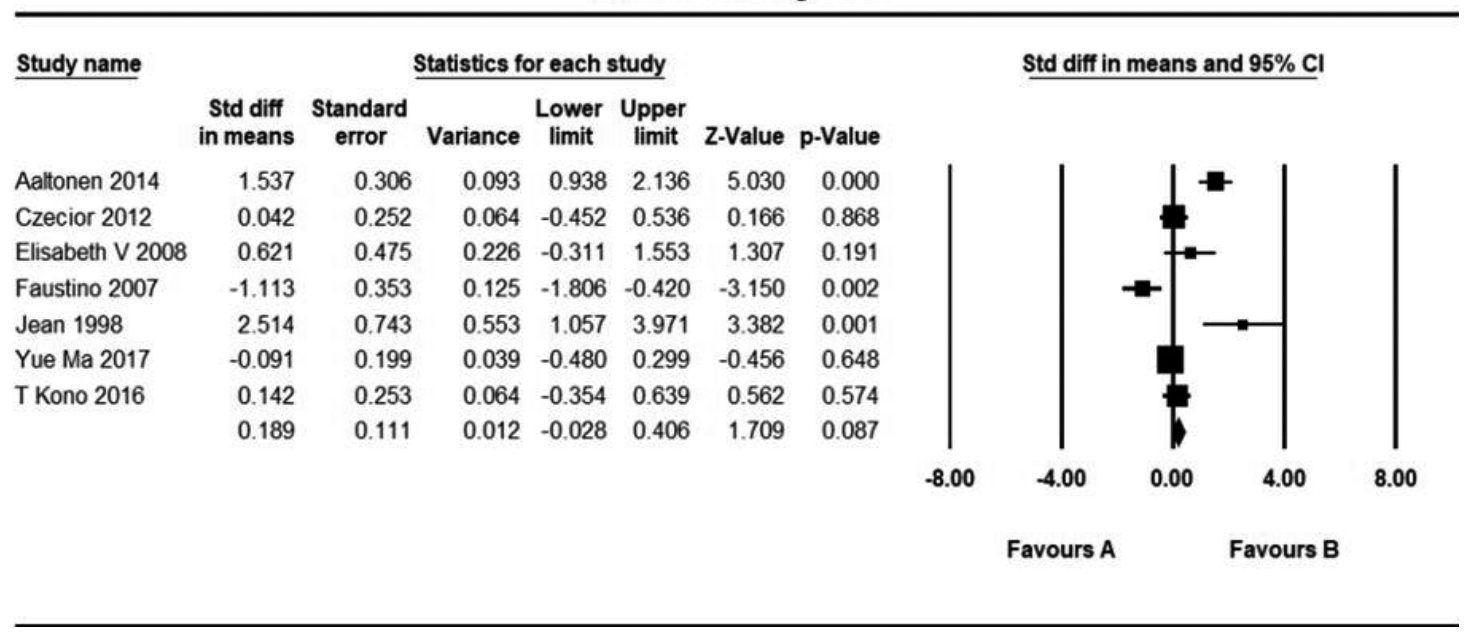

Fig. 4. Forest plot of breathiness. Std diff, standardized difference; $\mathrm{Cl}$, confidence interval.

\section{Meta Analysis}

\begin{tabular}{|c|c|c|c|c|c|c|c|c|c|c|c|c|}
\hline \multirow[t]{2}{*}{ Study name } & \multicolumn{7}{|c|}{ Statistics for each study } & \multicolumn{5}{|c|}{ Std diff in means and $95 \% \mathrm{Cl}$} \\
\hline & $\begin{array}{c}\text { Std diff } \\
\text { in means }\end{array}$ & $\begin{array}{l}\text { Standard } \\
\text { error }\end{array}$ & Variance & $\begin{array}{l}\text { Lower } \\
\text { limit }\end{array}$ & $\begin{array}{c}\text { Upper } \\
\text { limit }\end{array}$ & Z-Value & p-Value & & & & & \\
\hline Aaltonen 2014 & 1.131 & 0.289 & 0.084 & 0.564 & 1.698 & 3.911 & 0.000 & | & & & & $\rightarrow$ \\
\hline Czecior 2012 & 0.140 & 0.253 & 0.064 & -0.355 & 0.635 & 0.556 & 0.578 & & & & & \\
\hline Faustino 2007 & 1.244 & 0.359 & 0.129 & 0.540 & 1.948 & 3.462 & 0.001 & & & & & \\
\hline Yue Ma 2017 & -0.180 & 0.199 & 0.040 & -0.570 & 0.210 & -0.904 & 0.366 & & & & & \\
\hline \multirow[t]{4}{*}{ T Kono 2016} & -0.077 & 0.253 & 0.064 & -0.573 & 0.420 & -0.303 & 0.762 & & & & & \\
\hline & 0.257 & 0.115 & 0.013 & 0.033 & 0.482 & 2.247 & 0.025 & & & & & \\
\hline & & & & & & & & -1.00 & -0.50 & 0.00 & 0.50 & 1.00 \\
\hline & & & & & & & & & Favours A & & vours B & \\
\hline
\end{tabular}

Fig. 5. Forest plot of asthenia. Std diff, standardized difference; $\mathrm{Cl}$, confidence interval. 
Meta Analysis

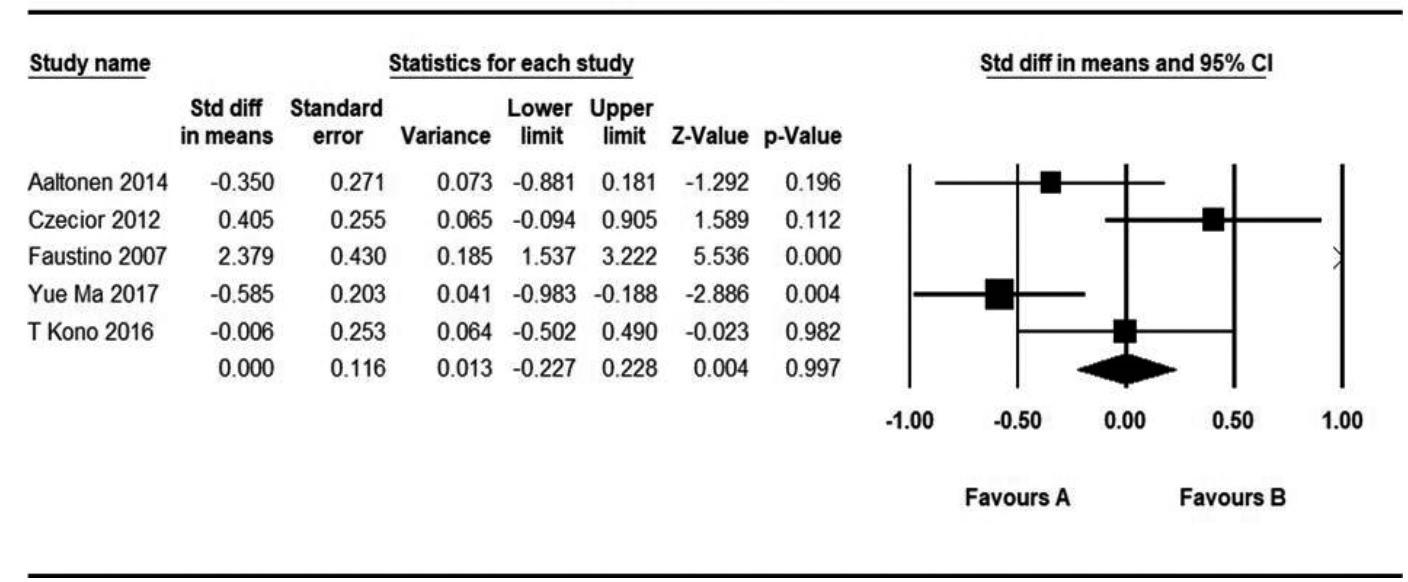

Fig. 6. Forest plot of strain. Std diff, standardized difference; Cl, confidence interval.

Meta Analysis

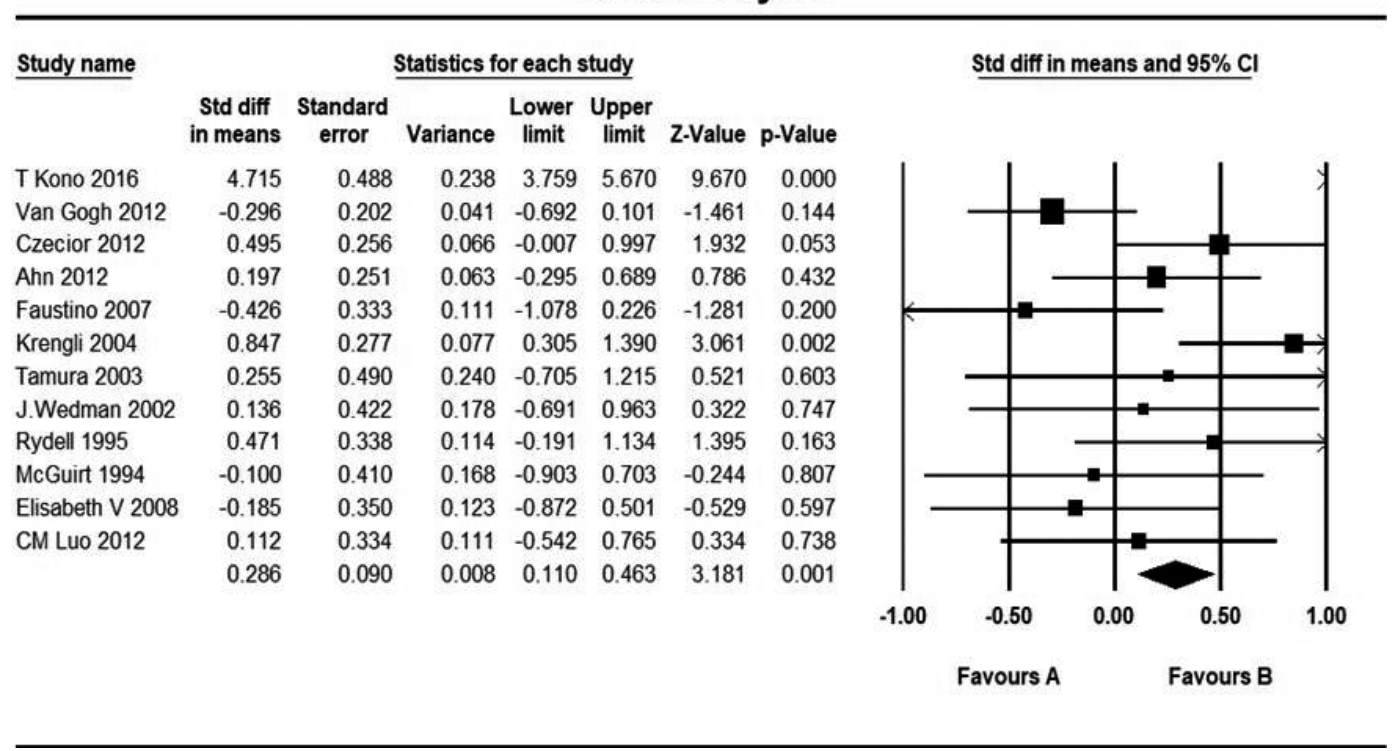

Fig. 7. Forest plot of jitter. Std diff, standardized difference; $\mathrm{Cl}$, confidence interval.

than LS treatment. Parameter S was analyzed in five studies. It showed no significant difference between LS and RT groups $(\mathrm{SMD}=0.000, \mathrm{SE}=0.116$, variance $=0.013,95 \% \mathrm{CI}:-0.227$ to 0.228 , z-value $=0.004, P=0.997$ ) (Fig. 6).

\section{Acoustic analysis}

The majority of these studies examined F0, jitter, and shimmer. Among acoustic analysis parameters, this study included jitter, shimmer, and NHR. Twelve studies provided adequate data related to jitter, with 307 patients in the LS group and 266 patients in the RT group. The forest plot of jitter is shown in Fig. 7. There was a significant difference in jitter between LS and RT (SMD= $0.286, \mathrm{SE}=0.090$, variance $=0.008,95 \% \mathrm{CI}: 0.110$ to 0.463 , $\mathrm{z}$-value $=3.181, P=0.001$ ) (Fig. 7). In the forest plot of jitter, RT was more effective than LS (Fig. 7). Fig. 8 shows shimmer and NHR of acoustic analysis. Shimmer analysis included 296 patients in LS and 253 patients in RT whereas NHR analysis included 64 patients in LS and 66 patients in RT. There were significant differences in shimmer $(\mathrm{SMD}=0.378, \mathrm{SE}=0.093$, variance $=0.009,95 \%$ CI: 0.196 to 0.560 , z-value $=4.073, P<0.001$ ) and NHR $(\mathrm{SMD}=0.959, \mathrm{SE}=0.224$, variance $=0.050,95 \% \mathrm{CI}$ : 0.519 to $1.398, \mathrm{z}$-value $=4.273, P<0.001$ ) (Fig. 9) between the two groups.

\section{DISCUSSION}

T1 and T2 early-stage glottic cancer is associated with lower 


\section{Meta Analysis}

\begin{tabular}{|c|c|c|c|c|c|c|c|c|c|c|c|c|}
\hline \multirow[t]{2}{*}{ Study name } & \multicolumn{7}{|c|}{ Statistics for each study } & \multicolumn{5}{|c|}{ Std diff in means and $95 \% \mathrm{Cl}$} \\
\hline & $\begin{array}{l}\text { Std diff } \\
\text { in means }\end{array}$ & $\begin{array}{c}\text { Standard } \\
\text { error }\end{array}$ & Variance & $\begin{array}{c}\text { Lower } \\
\text { limit }\end{array}$ & $\begin{array}{l}\text { Upper } \\
\text { limit }\end{array}$ & Z-Value & p-Value & & & & & \\
\hline T Kono 2016 & 4.797 & 0.494 & 0.244 & 3.830 & 5.765 & 9.715 & 0.000 & & & & & $y$ \\
\hline Van Gogh 2012 & -0.156 & 0.202 & 0.041 & -0.551 & 0.240 & -0.772 & 0.440 & & & & & \\
\hline Czecior 2012 & 0.506 & 0.256 & 0.066 & 0.004 & 1.008 & 1.975 & 0.048 & & & & & \\
\hline Ahn 2012 & 0.497 & 0.254 & 0.065 & -0.001 & 0.995 & 1.956 & 0.050 & & & & & \\
\hline Faustino 2007 & 0.229 & 0.330 & 0.109 & -0.417 & 0.876 & 0.695 & 0.487 & & & & & \\
\hline Krengli 2004 & 1.154 & 0.286 & 0.082 & 0.592 & 1.715 & 4.027 & 0.000 & & & & & \\
\hline Tamura 2003 & 0.593 & 0.497 & 0.247 & -0.381 & 1.567 & 1.194 & 0.233 & & & & & \\
\hline J.Wedman 2002 & -0.805 & 0.437 & 0.191 & -1.662 & 0.052 & -1.840 & 0.066 & & & & & \\
\hline Rydell 1995 & -0.316 & 0.335 & 0.113 & -0.974 & 0.341 & -0.943 & 0.346 & & & & & \\
\hline Elisabeth V 2008 & -0.180 & 0.350 & 0.123 & -0.867 & 0.506 & -0.514 & 0.607 & & & & & \\
\hline \multirow[t]{4}{*}{ CM Luo 2012} & 0.284 & 0.335 & 0.112 & -0.373 & 0.941 & 0.848 & 0.396 & & & & & \\
\hline & 0.378 & 0.093 & 0.009 & 0.196 & 0.560 & 4.073 & 0.000 & & & & & \\
\hline & & & & & & & & \multirow[t]{2}{*}{-1.00} & -0.50 & 0.00 & 0.50 & 1.00 \\
\hline & & & & & & & & & Favours $\mathrm{A}$ & & Favours B & \\
\hline
\end{tabular}

Fig. 8. Forest plot of shimmer. Std diff, standardized difference; $\mathrm{Cl}$, confidence interval.

\section{Meta Analysis}

\begin{tabular}{|c|c|c|c|c|c|c|c|c|c|c|c|c|}
\hline \multirow[t]{2}{*}{ Study name } & \multicolumn{7}{|c|}{ Statistics for each study } & \multicolumn{5}{|c|}{ Std diff in means and $95 \% \mathrm{Cl}$} \\
\hline & $\begin{array}{l}\text { Std diff } \\
\text { In means }\end{array}$ & $\begin{array}{c}\text { Standard } \\
\text { error }\end{array}$ & Varlance & $\begin{array}{l}\text { Lower } \\
\text { limit }\end{array}$ & $\begin{array}{l}\text { Upper } \\
\text { ilmit }\end{array}$ & Z-Value & p-Value & & & & & \\
\hline T Kono 2016 & 4.948 & 0.505 & 0.255 & 3.957 & 5.938 & 9.792 & 0.000 & I & 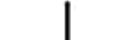 & & $1=$ & 1 \\
\hline \multirow[t]{4}{*}{ Ahn 2012} & -0.021 & 0.250 & 0.063 & -0.512 & 0.470 & -0.083 & 0.934 & & & & & \\
\hline & 0.959 & 0.224 & 0.050 & 0.519 & 1.398 & 4.273 & 0.000 & & & & & \\
\hline & & & & & & & & -8.00 & -4.00 & 0.00 & 4.00 & 8.00 \\
\hline & & & & & & & & & Favours A & & Favours B & \\
\hline
\end{tabular}

Fig. 9. Forest plot of noise to harmonic ratio. Std diff, standardized difference; $\mathrm{Cl}$, confidence interval.

morbidity and higher cure rate than advanced laryngeal cancer. Appropriate treatment can minimize its impact on voice. Thus, appropriate treatment plan needs to be established based on patient's sex, age, and mental state. If possible, a treatment method that maintains good phonation and respiratory function is desirable. Treatment methods for early glottic cancer include laser cordectomy (LC) and RT that can preserve voice [3,4]. As early glottic cancer is a disease affecting voice, a study analyzing voice after treatment with these two methods could facilitate patient decision-making. RT is one of the primary treatment modalities in patients with early glottic cancer with favorable outcomes. It can result in voice preservation [5].

Hong et al. [9] have investigated delayed tissue effects of human vocal fold following radiation therapy and found fibrotic changes in human superficial lamina propria and thyroarytenoid muscle impairing vocal fold closure, pliability, and dynamic changes in tension and length. They reported that, compared to surgery, RT improved voice quality as laryngeal edema subsided after surgery and restored the original function and appearance of the larynx [9]. However, many complications are associated with RT as mentioned earlier.

LC is an endoscopic laryngeal surgery in which the lesion is excised using a laser after appropriate laryngeal exposure under general anesthesia. The range of cordectomy is determined according to the European Laryngological Society classification. In general, the lesion is excised with a $2-\mathrm{mm}$ border and electrocautery is used in the area that is beyond reach of the laser. LC is associated with a minimal risk of laryngeal edema after the surgery. It has low morbidity rate and less side effects. It can be performed repeatedly. Therefore, LC represents a better surgical option for patients with early glottic cancer because it has fewer complications. In addition, it is more likely to preserve voice in 
the long term [13]. LC does not exclude other treatment methods. It is also easy to detect cancer recurrence [6]. However, as LC leaves 1-3 mm residual lesion during resection to preserve the voice, it may not sufficiently remove the tumor. Thus, tumor recurrence is possible [14]. Several attempts have been made to minimize damage to voice quality by subdividing the resection range [15].

A number of studies have been conducted to determine voice quality of patients with early glottic cancer after RT and LC. Most of these studies focused on voice acoustic analysis, psychoacoustic analysis using GRBAS scale with analysis of voice handicap index, and comparison of quality of life after surgery [16]. However, in previous studies, no significant differences in F0, jitter, or shimmer were found, although MPT was slightly longer in the RT group than that in the LC group $[7,8]$. The difference in MPT and shimmer between the two groups suggests that patients who have received RT might have better voice than those who have received LC. A study comparing voice handicap index and the quality of life has shown that the group that underwent LC has statistically better results $[15,16]$. In addition, the LC group showed similar MPT and acoustic parameters to the normal group and voice after LC was similar to that after RT. Thus, LC can be recommended as a cost-effective intervention with a reasonable voice outcome [7]. The RT group showed more severe insufficiency of glottal closure due to laryngeal stroboscopy than the LC group, suggesting ventricular closure during phonation and hyperadduction of the arytenoid cartilage. According to a psychoacoustic analysis [10-12,17], patients who received RT had higher frequency of normal or mild coarse voice whereas those who received LC exhibited higher frequency of moderate or severe coarse voice, indicating that RT was better than LC [18-24]. However, Tamura et al. [20] have revealed that both groups show similar voice preservation results, suggesting that LC does not affect the voice considerably. Hong et al. [9] reported that even though evaluation of stop consonants was not always performed clinically and clinical difference might be subtle, significant differences were observed in certain measures at group level. Changes in voice onset time and vowel can result in decreased speech intelligibility in the RT group. Thus, LS might be superior to radiation therapy in terms of speech production.

In this study, we conducted a meta-analysis of two modalities for early-stage glottic cancer. Our results revealed better acoustic analysis parameters and perceptual outcome in patients treated with RT compared with those treated with LS. We compared parameters of acoustic analysis (jitter, shimmer, and NHR) and parameters of perceptual analysis (GRBAS) in early glottic cancer through a meta-analysis. The meta-analysis included the following studies: van Gogh et al. [17], Luo et al. [10], Czecior et al. [11],Ahn et al. [12], Nunez Batalla et al. [18], Wedman et al. [21], and McGuirt et al. [24]. We found no significant differences between LS and RT groups in acoustic analysis parameters. Kono et al. [13] and Krengli et al. [19] have shown significant differences in jitter, shimmer, and NHR between the two modalities, with more favorable values shown in the RT group. However, Rydell et al. [23] reported that RT was more effective than LS in jitter in acoustic analysis.

Our meta-analysis of acoustic parameters suggested significant differences between patients treated with LS and RT according to jitter, shimmer, and NHR. When comparing acoustic analysis between the two modalities, jitter, shimmer, NHR had more favorable values in the RT group than those in the LS group, similar to results Kono et al. [13] and Sjogren et al. [14]. With respect to GRBAS of perceptual analysis, Czecior et al. [11] and Sjogren et al. [14] have shown no significant differences between the two treatments. However, Ma et al. [16] found that patients treated with RT exhibited greater roughness and strain than patients treated with LS, although no differences in breathiness or asthenia were noted. Aaltonen et al. [15] found that RT results showed statistically significant differences in B and A than transoral LS, although G, R, and S were similar between the two treatment groups. Rydell et al. [23] found that RT treatment was better than LS in terms of B. By contrast, Rosier et al. [22] found no difference in $B$ between the two options.

In summary, our study found significant differences in $G$ and A of GRBAS scale between LS and RT. Voice quality in patients treated with RT tended to be better than that in patients who were treated with LS. Results of this meta-analysis suggest significant differences in voice quality following RT and LS for the treatment of early glottic cancer. However, this study has limitations related to a relatively small sample size for meta-analysis. In addition, most of the included studies were retrospective in design. Moreover, our study lacked data related to LS types and radiation doses for RT.

Our meta-analysis showed that voice quality in perceptual and acoustic analysis was significantly better in patients who were treated with RT compared with patients who underwent LS. RT may enhance voice quality in early-stage glottic cancer. Further well-designed, multicenter, and randomized controlled studies are needed. Widening the search to languages beyond English and Korean might return a significantly higher number of quality articles.

\section{CONFLICT OF INTEREST}

No potential conflict of interest relevant to this article was reported.

\section{ORCID}

So Hyun Lee https://orcid.org/0000-0003-3367-2690

Yong Tae Hong https://orcid.org/0000-0001-7584-5823 


\section{AUTHOR CONTRIBUTIONS}

Conceptualization: KHH. Data curation: SHL. Formal analysis: SHL, JSK. Methodology \& Project administration: SHL, YTH. Visualization \& Writing - original draft: SHL.Writing - review \& editing:YTH.

\section{REFERENCES}

1. Ferlay J, Shin HR, Bray F, Forman D, Mathers C, Parkin DM. Estimates of worldwide burden of cancer in 2008: GLOBOCAN 2008. Int J Cancer. 2010 Dec;127(12):2893-917.

2. Chu EA, Kim YJ. Laryngeal cancer: diagnosis and preoperative workup. Otolaryngol Clin North Am. 2008 Aug;41(4):673-95.

3. Laoufi S, Mirghani H, Janot F, Hartl DM. Voice quality after treatment of T1a glottic cancer. Laryngoscope. 2014 Jun;124(6):1398401.

4. Lee HH, Lee KD, Lee HK, Pyo KB, Ahn KM, Lee YS. Treatment results and voice analysis after laser cordectomy for glottic T1 cancer. Korean J Otorhinolaryngol Head Neck Surg. 2002 Aug;45(8):80510.

5. Brandenburg JH. Laser cordotomy versus radiotherapy: an objective cost analysis. Ann Otol Rhinol Laryngol. 2001 Apr;110(4):312-8.

6. Higgins KM, Shah MD, Ogaick MJ, Enepekides D. Treatment of earlystage glottic cancer: meta-analysis comparison of laser excision versus radiotherapy. J Otolaryngol Head Neck Surg. 2009 Dec;38(6): 603-12.

7. Greulich MT, Parker NP, Lee P, Merati AL, Misono S. Voice outcomes following radiation versus laser microsurgery forT1 glottic carcinoma: systematic review and meta-analysis. Otolaryngol Head Neck Surg. 2015 May;152(5):811-9.

8. Huang G, Luo M, Zhang J, Liu H. The voice quality after laser surgery versus radiotherapy of T1a glottic carcinoma: systematic review and meta-analysis. Onco Targets Ther. 2017 May;10:2403-10.

9. Hong YT, Park MJ, Hong KH. Characteristics of speech production in patients with T1 glottic cancer who underwent laser cordectomy or radiotherapy. Logoped PhoniatrVocol. 2018 Oct;43(3):120-8.

10. Luo CM, Fang TJ, Lin CY, Chang JT, Liao CT, Chen IH, et al. Transoral laser microsurgery elevates fundamental frequency in early glottic cancer. JVoice. 2012 Sep;26(5):596-601.

11. Czecior E, Orecka B, Pawlas P, Mrowka-Kata K, Namyslowski G, Skladowski K, et al. Comparative assessment of the voice in patients treated for early glottis cancer by laser cordectomy or radiotherapy. Otolaryngol Pol. 2012 Nov-Dec;66(6):407-12.

12. Ahn SH, Kim JH, Lee SH, Kim WJ, Kim DH, Park YH, et al. Comparison of voice outcomes in early glottic cancer patients after laser surgery or radiotherapy. Korean J Otorhinolaryngol Head Neck Surg. 2012 Nov;55(11):701-6.

13. Kono T, Saito K, Yabe H, Uno K, Ogawa K. Comparative multidimensional assessment of laryngeal function and quality of life after radiotherapy and laser surgery for early glottic cancer. Head Neck. 2016 Jul;38(7):1085-90.

14. Sjogren EV, van Rossum MA, Langeveld TP, Voerman MS, van de Kamp VA, Friebel MO, et al. Voice outcome in T1a midcord glottic carcinoma: laser surgery vs radiotherapy. Arch Otolaryngol Head Neck Surg. 2008 Sep;134(9):965-72.

15. Aaltonen LM, Rautiainen N, Sellman J, Saarilahti K, Makitie A, Rihkanen $\mathrm{H}$, et al. Voice quality after treatment of early vocal cord cancer: a randomized trial comparing laser surgery with radiation therapy. Int J Radiat Oncol Biol Phys. 2014 Oct;90(2):255-60.

16. Ma Y, Green R, Pan S, McCabe D, Goldberg L, Woo P. Long-term voice outcome following radiation versus laser microsurgery in early glottic cancer. JVoice. 2019 Mar;33(2):176-82.

17. van Gogh CD,Verdonck-de Leeuw IM, Wedler-Peeters J, Langendijk JA, Mahieu HF. Prospective evaluation of voice outcome during the first two years in male patients treated by radiotherapy or laser surgery for T1a glottic carcinoma. Eur Arch Otorhinolaryngol. 2012 Jun;269(6):1647-52.

18. Nunez Batalla F, Caminero Cueva MJ, Senaris Gonzalez B, Llorente Pendas JL, Gorriz Gil C, Lopez Llames A, et al. Voice quality after endoscopic laser surgery and radiotherapy for early glottic cancer: objective measurements emphasizing the Voice Handicap Index. Eur Arch Otorhinolaryngol. 2008 May;265(5):543-8.

19. Krengli M, Policarpo M, Manfredda I, Aluffi P, Gambaro G, Panella $\mathrm{M}$, et al. Voice quality after treatment for T1a glottic carcinoma-radiotherapy versus laser cordectomy. Acta Oncol. 2004;43(3):284-9.

20. Tamura E, Kitahara S, Ogura M, Kohno N. Voice quality after laser surgery or radiotherapy for T1a glottic carcinoma. Laryngoscope. 2003 May;113(5):910-4.

21. Wedman J, Heimdal JH, Elstad I, Olofsson J.Voice results in patients with T1a glottic cancer treated by radiotherapy or endoscopic measures. Eur Arch Otorhinolaryngol. 2002 Nov;259(10):547-50.

22. Rosier JF, Gregoire V, Counoy H, Octave-Prignot M, Rombaut P, Scalliet $\mathrm{P}$, et al. Comparison of external radiotherapy, laser microsurgery and partial laryngectomy for the treatment of T1N0M0 glottic carcinomas: a retrospective evaluation. Radiother Oncol. 1998 Aug;48(2):175-83.

23. Rydell R, Schalen L, Fex S, Elner A. Voice evaluation before and after laser excision vs. radiotherapy of T1A glottic carcinoma. Acta Otolaryngol. 1995 Jul;115(4):560-5.

24. McGuirt WF, Blalock D, Koufman JA, Feehs RS, Hilliard AJ, Greven $\mathrm{K}$, et al. Comparative voice results after laser resection or irradiation ofT1 vocal cord carcinoma. Arch Otolaryngol Head Neck Surg. 1994 Sep;120(9):951-5. 